NASA Technical Memorandum 106931

\title{
Grid Orthogonality Effects on Predicted Turbine Midspan Heat Transfer and Performance
}

R.J. Boyle

Lewis Research Center

Cleveland, Ohio

and
A.A. Ameri
University of Kansas
Lawrence, Kansas

Prepared for the

39th International Gas Turbine and Aeroengine Congress and Exposition sponsored by the American Society of Mechanical Engineers

The Hague, Netherlands, June 13-16, 1994

National Aeronautics and

Space Administration 


\title{
GRID ORTHOGONALITY EFFECTS ON PREDICTED TURBINE MIDSPAN HEAT TRANSFER AND PERFORMANCE
}

\author{
R. J. Boyle \\ NASA Lewis Research Center \\ Cleveland, $\mathrm{OH} 44135$ \\ A. A. Ameri \\ University of Kansas \\ Center for Research, Inc. \\ Lawrence, KS 66045
}

\begin{abstract}
The effect of five different $\mathrm{C}$ type grid geometries on the predicted heat transfer and aerodynamic performance of a turbine stator is examined. Predictions were obtained using two flow analysis codes. One was a finite difference analysis, and the other was a finite volume analysis. Differences among the grids in terms of heat transfer and overall performance were small. The most significant difference among the five grids occurred in the prediction of pitchwise variation in total pressure. There was consistency between results obtained with each of the flow analysis codes when the same grid was used. A grid generating procedure in which the viscous grid is embedded within an inviscid type grid resulted in the best overall performance.
\end{abstract}

\section{Nomenclature}

$\begin{array}{ll}c & - \text { True chord } \\ c_{x} & - \text { Axial chord } \\ \bar{e} & - \text { Kinetic energy loss coefficient } \\ M_{2} & - \text { Isentropic exit Mach No. } \\ P^{\prime} & - \text { Total pressure } \\ R e_{2} & - \text { Reynolds No. based on } c_{x} \text { and } M_{2} \\ s & - \text { Surface distance } \\ S t & - \text { Stanton No. based on } U_{\text {INLET }} \text { and } \rho \\ T u & - \text { Turbulence intensity } \\ U & - \text { Velocity } \\ Y & - \text { Loss coefficient, } Y=\Delta P^{\prime} / 0.5 \rho U_{\mathrm{EXIT}}^{2} \\ y_{1}^{+} & - \text {Distance of first grid line from blade } \\ \eta & - \text { Direction outward from blade surface } \\ \rho & - \text { Density } \\ \text { Subscripts } & \\ \text { EXIT } & - \text { Exit of computational domain } \\ \text { INLET } & - \text { Inlet of computational domain } \\ \text { M } & - \text { Measurement plane } \\ \text { S } & - \text { Surface of blade }\end{array}$

\section{INTRODUCTION}

One of the goals for Navier-Stokes turbomachinery analysis is the accurate predictions of blade row losses and turbine blade heat transfer. It has been shown by a number of investigators that the characteristics of the grids used can significantly affect the predicted results. Davis, Hobbs and Weingold(1988) investigated the effects of blade-to-blade grids of different densities on the prediction of compressor performance. Recently, attention has also been given to the desirability of using grids orthogonal to the blade surfaces. Many applications using C-type grids have used grids generated in a manner similar to that proposed by Sorenson(1980) in which the points on the cut line have the same coordinates for both the upper and lower portions of the grid. It was shown by Arnone, Liou, and Povinelli(1992) that C type grids can be highly skewed, especially for highly turned modern turbine stator blades. The skewing is most evidenced when a matching condition is enforced on the cut line from the trailing edge to the downstream boundary. If the matching condition is removed the result is less skewed grids. The cut line divides the $\mathrm{C}$ grid, and extends from the trailing edge to the downstream boundary. Arnone et al.(1992) proposed the use of C-type grids for turbine applications in which the requirement for common coordinates along the cut line is not enforced. This procedure allows for greater grid orthogonality at the blade surface, since the number of grid cells on the upper and lower surfaces are not necessarily equal. However, this procedure requires interpolation along the cut line, rather than averaging the solution at a common point. Micklow, Shivaraman, and $\operatorname{Li}(1993)$ took this process further, and presented results where the requirement for matching points was not enforced along the outer boundary of the blade-toblade grid, as well as along the cut line.

Yeuan, Hamed, and Tabakoff(1993) used nonperiodic $\mathrm{H}$ grid to analyze the performance of a turbine cascade. Turner, Liang, Beauchamp, and Jen- 
nions(1993) advance arguments for the use of modified H grids, called I grids, to improve flow field calculation accuracy. The $\mathrm{H}$ grids were modified so as to be more orthogonal to the blade surface, and were recommended for use in calculating the performance of highly turned turbine blades. Because of the rapid changes in heat transfer in the leading edge region $\mathrm{C}$ or $\mathrm{O}$ type grids are advantageous in comparison to $\mathrm{H}$ or I type grids for use in Navier-Stokes heat transfer analyses. C type grids have the advantage relative to $\mathrm{O}$ type grids in that only a single grid is needed for a blade row passage. O type grids are generally embedded within a $\mathrm{H}$ type grid for cascade analyses. The work that is reported in the present paper is concerned with determining the effects of different $\mathrm{C}$ type grids on turbine blade heat transfer, as well as turbine blade aerodynamic performance.

The issue of grid size is especially important when one considers that the goal of code development work is to achieve accurate three-dimensional Navier-Stokes solutions while utilizing a reasonable amount of computer resources. It has been shown by Boyle and Giel(1992) that over 50 spanwise grid planes are necessary to achieve grid independent heat transfer results for a typical turbine blade. If one wishes to limit the size of routine three dimensional Navier-Stokes calculations to around a half million grid points, then blade-to-blade grids would have a maximum of 10,000 points.

The choice of the best blade-to-blade grid is facilitated by comparisons with experimental data. Arts, Lambert de Rouvroit, and Rutherford(1990) presented data for the midspan region of a turbine stator with an exit flow angle of $74^{\circ}$. Heat transfer, pitchwise variation in total pressure, as well as overall stator performance data were given. These data were used by Harasagama, Tarada, Baumann, Crawford, and Neelakantan(1993) to compare different approaches for the prediction of turbine blade heat transfer using boundary layer methods. Luo and Lakshminarayana(1993) used the same experimental data to show the validity of their method for predicting the flowfield and heat transfer in a turbine passage using a Navier Stokes analysis.

In the present work blade surface heat transfer as well as aerodynamic performance are examined for five different baseline grids. Additional grids were generated to examine other possible grid effects. Three of the five baseline grids have a matching condition imposed along the cut line. Among these three grids two are similar, and differ only in the procedure used to generate them. One was generated using a single grid solution generated using the GRAPE code of Soren$\operatorname{son}(1980)$. The other was generated using the code of Arnone et al.(1992) in which the viscous grid is gen- erated by embedding a near wall grid within a sparse inviscid grid. The third grid that is periodic along the cut line differs from the other two in that the grid in the wake region expands to have nearly uniform pitchwise spacing at the downstream boundary. The two grids without the matching condition differ from each other downstream of the blade row. One extends the periodic boundary in a straight line, so that there is little flow across the periodic boundary downstream of the blade. The other curves the grid, so that there are large flows across the periodic boundary downstream of the blade.

The choice of grid could be significantly affected by the Navier-Stokes solution methodology. The NavierStokes analysis were done using a finite difference code developed by Chima(1987), and a finite volume code developed by Arnone et al.(1992). Since the choice of calculation procedure is affected by far more factors than are explored in this paper, the emphasis is on determining the best grid approach for each code. Similarly, since the emphasis is on grid effects, a simple approach is taken to turbulence modeling. A mixing length turbulence model is used.

\section{DESCRIPTION OF ANALYSIS}

Grid characteristics. All five grids were of of the same size, $177 \times 53$. This size was chosen based on requirements for three-dimensional Navier-Stokes analyses. Certainly, two-dimensional Navier-Stokes results could be obtained in a reasonable CPU time for grids of larger sizes. However, based on the required number of spanwise grids for three dimensional heat transfer analyses, the CPU time and core memory required for three-dimensional analyses might be excessive for blade-to-blade grids significantly greater than $177 \times 53$. All grids,except grid $A$, had the inlet boundary $0.55 c_{x}$ ahead of the vane. Grid A began $0.75 c_{x}$ in front of the vane. All grids had their downstream boundary at $0.84 c_{x}$ behind the vane trailing edge. The downstream boundary was chosen so that the measurement station used by Arts, Lambert de Rouvroit, and Rutherford(1990) was midway between the trailing edge and the downstream boundary. The near wall spacing was held constant at $4 \times 10^{-5} c_{x}$ for all baseline grids. The effect of variations in the near wall spacing on predicted results is examined. 

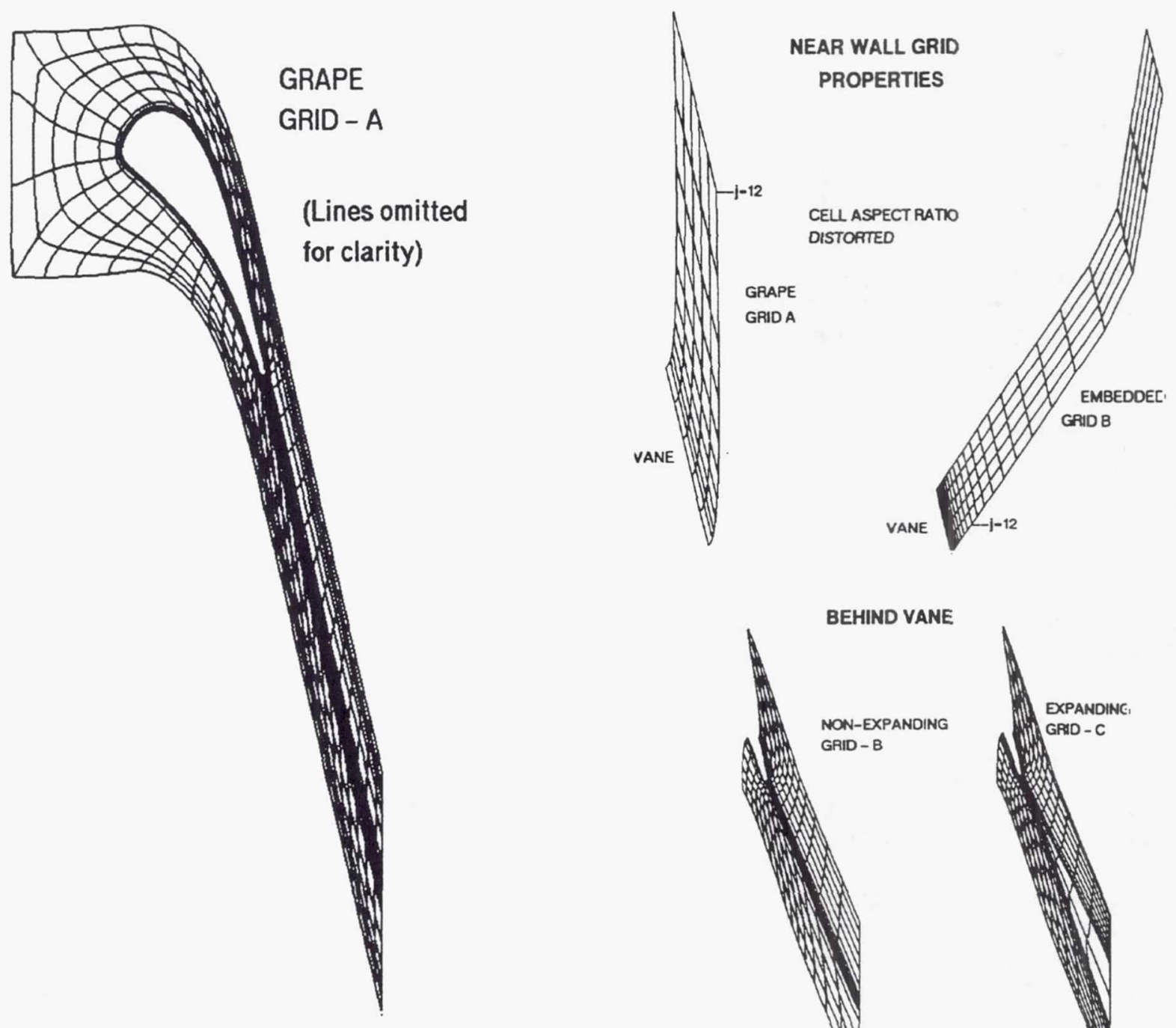

MATCHING \& NON-MATCHING WAKE CUT LINES
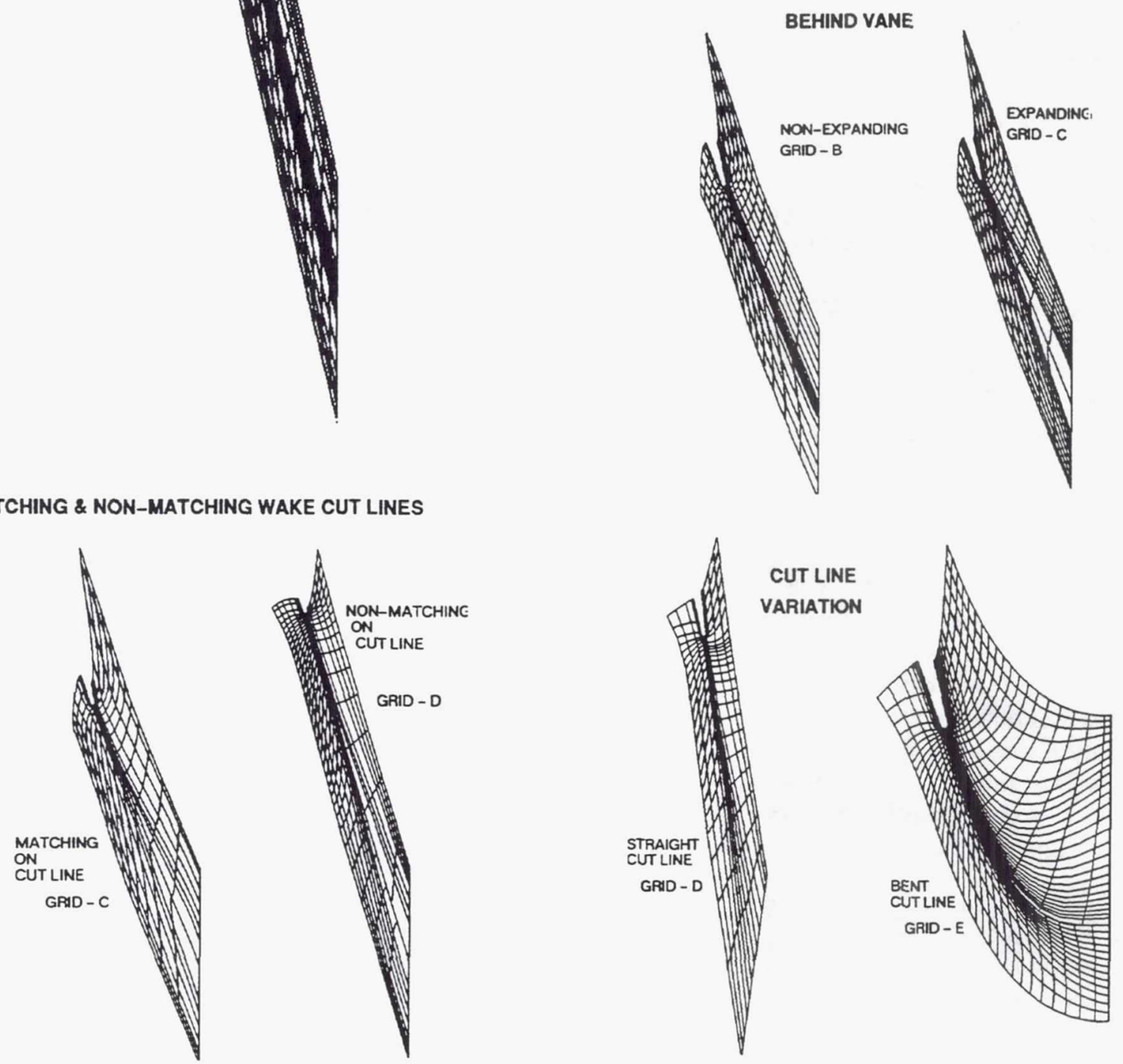

Fig.1 - Description of grids used in analysis 
The five grids used in the analysis are illustrated in figure 1 , and will be referred to with the labels $A$ through $\mathrm{E}$. Table I give the number of grid spacing used in each of the baseline C-type grids. Grid A was generated using the GRAPE code of Sorenson(1980). This code obtains a solution to a two-dimensional Poisson partial differential equation in order to generate a C-type grid. Grid B was generated using the code developed by Arnone et al.(1992), and as can be seen in figure 1 , this grid is very similar to grid $A$. The principal difference is that a two step grid generation process was used to generate grid B. First a coarse grid, such as might be used in an inviscid analysis is generated. This initial grid has relatively few lines in the blade-to-blade direction. The grid used for the viscous calculations is obtained by embedding a fine grid over a few cells in the near wall region. The remaining three grids were generated using the same procedure as grid B. Grid C differed from grid $B$ in that the grid lines for small values of $\eta$ do not maintain a constant spacing from the cut line between the trailing edge and the downstream boundary. For grid B these grid lines are maintained at a uniform spacing between the trailing edge and the downstream boundary. Grids D and E differed from grid $\mathrm{C}$ in that these two grids were not periodic along the cut line between the trailing edge and the downstream boundary. As can be seen in figure 1 , grids that are not periodic along the cut line can more easily be made orthogonal to the blade surface. One potential disadvantage of this approach however, is that the flow solution has to be interpolated along the cut line. Grid E differs from grid D in that downstream of the blade the periodic boundary is curved 80 that at the downstream boundary the $\eta=$ constant grid lines are parallel to the axial direction. Grids A through D are extended downstream of the blade at a constant angle, which is clooe to the trailing edge angle. When these grids are woed, there is only a single wake in the flow field. However, when grid $\mathrm{E}$ is used, multiple wakes are present in the flow field. The number of wakes depend on the flow angle and the distance between the trailing edge and the downstream boundary. At any given axial boation there is only a single passage flow field. Grids Dn and $E_{3}$ in table I are similar to grids D and E respectiively, but with more circumferential grid lines.

Table I. - Distribution of circumferential grid.

\begin{tabular}{|r|r|r|r|r|r|r|r|}
\hline & \multicolumn{7}{|c|}{ Grid } \\
\hline No. of increments & A & B & C & D & E & Dn & Ea \\
\hline Wake-pressure side & 40 & 40 & 40 & 56 & 56 & 88 & 128 \\
Blade-pressure side & 48 & 48 & 48 & 32 & 32 & 32 & 32 \\
Blade-suction side & 48 & 48 & 48 & 64 & 64 & 96 & 96 \\
Wake-suction side & 40 & 40 & 40 & 24 & 24 & 24 & 64 \\
\hline
\end{tabular}

Flow analysis. Two flow analysis codes were run for each of the five grids. One analysis used a finite difference approach, and was developed by Chima(1987). In the discussion which follows, results obtained using this code are labeled as flow code FC. The other analysis, developed be Arnone et al.(1992), used a finite volume approach, and employed a multi-grid solution scheme. Results obtained using this code are labeled as flow code FA. While the discretization is different between the two analyses, both used a time marching approach with an explicit four stage Runge-Kutta scheme to solve the differential equations. Both also employed implicit residual smoothing.

The turbulence model used in both flow analyses is a variation of the model developed by Baldwin and Lomax(1978). The main difference between the model used and the Baldwin-Lomax model is in the prediction of the transition location. The transition model given by Mayle(1991) was used. In this model the location of the start of transition as well as the length of transition are given as functions of Reynolds number and turbulence intensity. It was found that estimating the local freestream turbulence intensity rather than just using the inlet frestream turbulence intensity gave a better estimate of the vane heat transfer for the cases examined. The local freestream turbulence intensity was estimated assuming that the velocity fluctuations remain constant through the the passage. This assumption results in:

$$
T u_{\mathrm{S}}=T u_{\text {INLET }} U_{\text {INLET }} / U_{\mathrm{S}}
$$

The local velocity, $U_{\mathrm{S}}$, was calculated from the isentropic relationship and the local static-to-inlet total pressure ratio.

\section{RESULTS}

Heat Transfer Comparisons. Figures 2 and 3 show the variation in heat transfer among the different grids for the two flow solution codes. Also shown in each figure are the experimental data of Arts et al.(1990). These comparisons are for $R e_{2}=1.16 \times 10^{6}, T u_{\text {INLET }}=1 \%$, and $M_{2}=0.84$. Because of the low inlet turbulence, transition did not occur even though the Reynlods number is fairly high. The Stanton number predictions shown in figure 2 show very high heat transfer just near the trailing edge. These results were obtained by forcing the flow turbulent at the tangent point of the vane trailing edge circle. Since the focus of this work is on the effects of different grids on predicted results, it is useful to show comparisons for a laminar flow case. For 


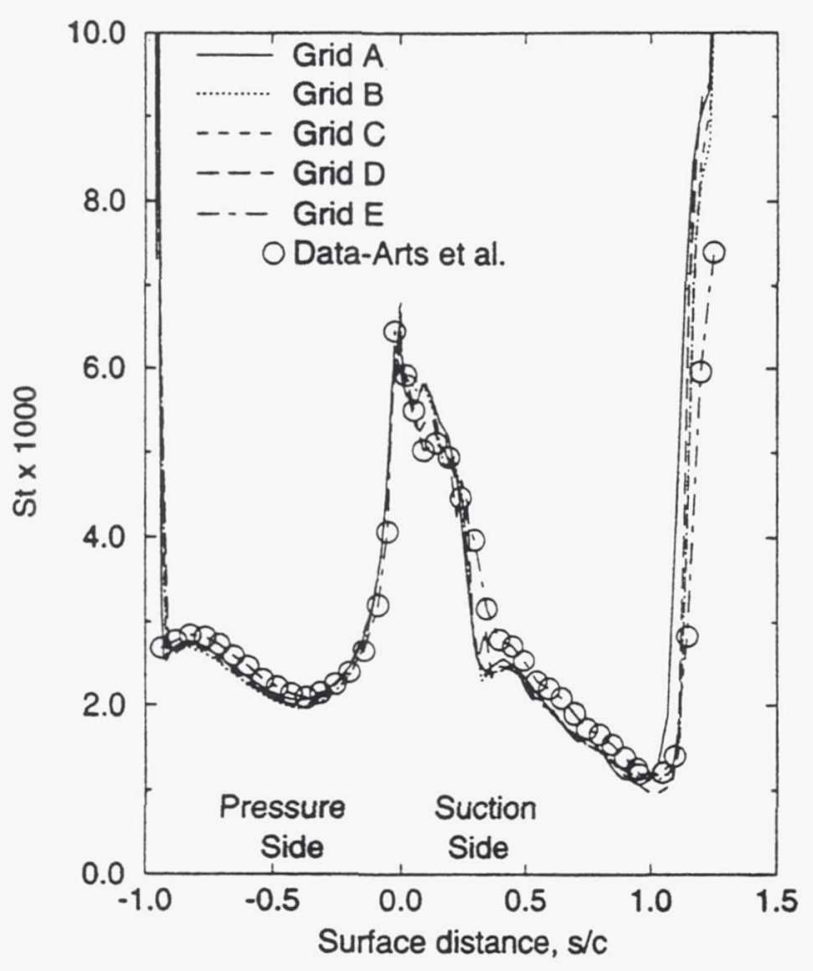

Fig. 2 Stanton number comparisons for $R e_{2}=1.16 \times$ $10^{6}, T u=1 \%, M_{2}=0.84$, Flow code FA.

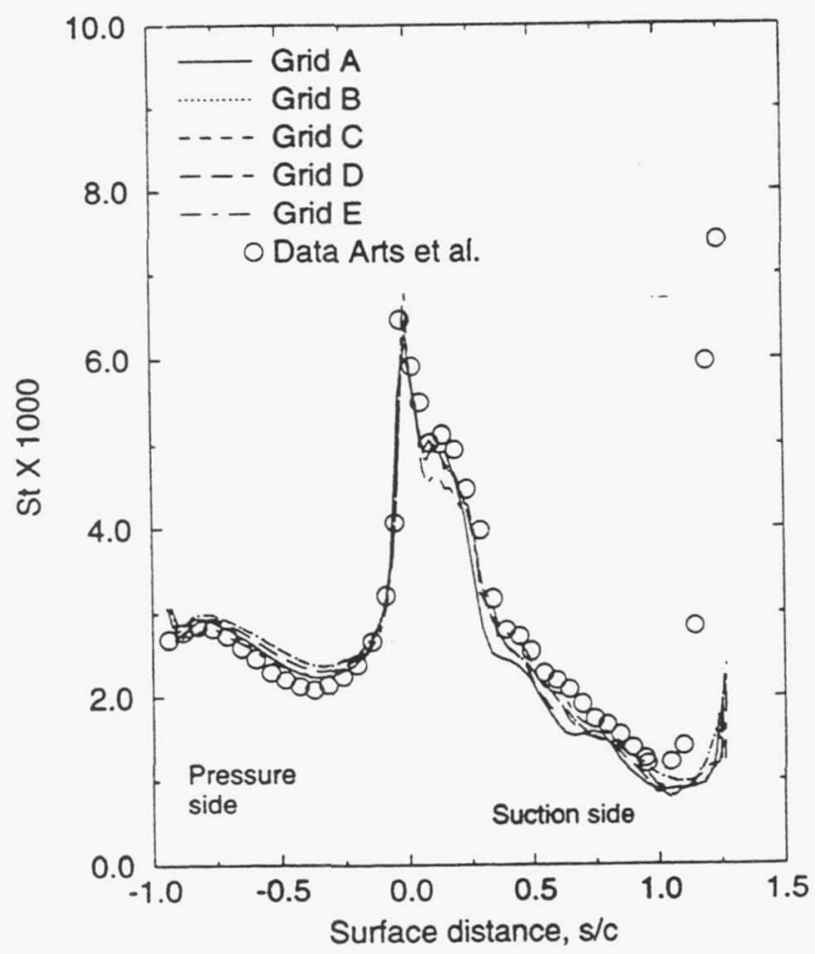

Fig. 3 Stanton number comparisons for $R e_{2}=1.16 \times$ $10^{6}, T u=1 \%, M_{2}=0.84$, Flow code FC.

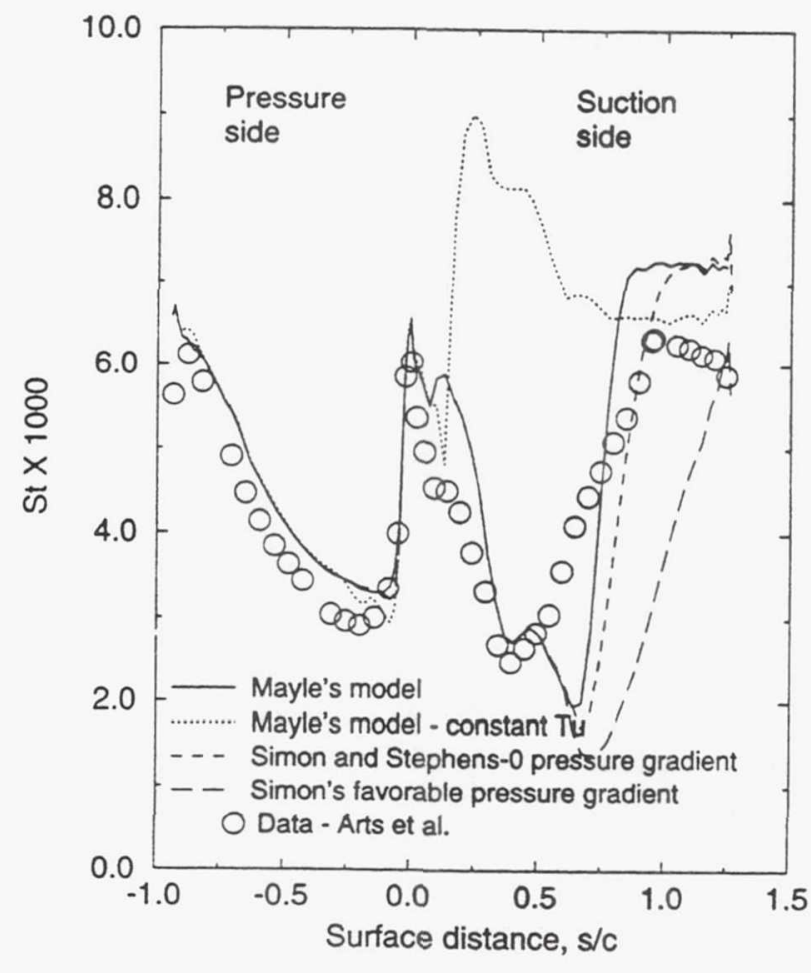

Fig. 4 Effect of transition model assumptions on predicted heat transfer, $R e_{2}=2.1 \times 10^{6}, T u=6 \%, M_{2}=$ 0.92 , Flow code FC, grid C.

laminar flow, questions regarding the implementation of the turbulence model do not arise. For each of the flow analyses, the variation in blade heat transfer among the five grids is small. Exept very close to the trailing edge, both codes give nearly the same level of heat transfer for the same grid. In flow code FA the boundary layer was set to be fully turbulent at the beginning of the trailing edg circle. The agreement with the experimental data is generally good, and for this case there is little evidence to prefer one grid over another.

The heat transfer predictions are in good agreement with the experimental data for the low turbulence intensity case. Comparisons will next be made for a case with high turbulence intensity, and high Reynolds number. The results of different approaches to modeling the effects of a high turbulence intensity will be examined prior to showing the grid effects. Figure 4 shows the effects of transition model assumptions on vane surface heat transfer for the highest Reynolds number, $2.1 \times 10^{6}$, and highest turbulence intensity, $6 \%$, tested by Arts et al(1990). The exit Mach number was 0.92. Results are shown for a single grid, (grid C), and flow solution code, (FC). The purpose of this figure is to illustrate the significance of the transition model for the heat transfer predictions. The model for the start of transition 
proposed by Mayle(1991) more accurately predicts the start of transition when the turbulence intensity is adjusted to account for the local inviscid velocity. This is especially evident on the suction surface. Comparing the slope of the predicted heat transfer with the experimental data shows that the length of transition on the suction surface is not well predicted using the intermittency model proposed by Mayle(1991). The predicted transition length is shorter than that indicated by the experimental data. Heat transfer predictions are shown for two additional transition length models. These are the transition length models of Simon and Stephens(1991) and Simon(1994). The model of Simon and Stephens was developed for zero pressure gradient flows, while Simon's model was developed for flows with favorable pressure gradient. The use of Simon's transition length model results in good agreement with the experimental data. Even though suction surface transition began close to the uncovered portion of the suction surface, there was a favorable pressure gradient at the start of transition. These results illustrate the sensitivity of the heat transfer results to transition assumptions. Because of the high freestream turbulence intensity, pressure surface transition occurs close to the leading edge. The heat transfer on the pressure surface is accurately predicted.

Figure 5 shows the effect of different model assumptions for predicting the effect of freestream turbulence on blade surface heat transfer. Heat transfer predictions are shown using the model of Forrest(1970), as well as when no augmentation due to freestream turbulence is assumed. This model for calculating an eddy viscosity due to freestream turbulence was applied only prior to transition. It was applied in an analogous fashion to the Baldwin-Lomax eddy viscosity model, which is used after transition occurs. The Baldwin-Lomax model for turbulent eddy viscosity is a two layer model. Predictions are shown when the augmentation model is applied only in the inner layer; when it is applied to both layers; and when it is held constant in the outer layer. This model for the augmentation of eddy viscosity is utilized only prior to transition. The best overall agreement with the experimental data is achieved when the turbulent eddy viscosity in the outer layer is held constant at the inner layer value determined at the point where the two layers meet.

A comparison of the heat transfer predictions for the five different grids is given in figures 6 and 7 . Since this is a relative comparison, only Mayle's transition model is utilized. The use of this model results in a relatively long portion of the suction surface being turbulent, and allows for the comparisons for different grids to be done for a case with turbulent flow on both pressure and suction surfaces. In this case the pressure surface is mostly turbulent, and half of the suction surface is turbulent. The variation in blade surface heat transfer among the five grids is small. The results for this test case are similar to those shown in figures 2 and 3 for a case where the vane surface heat transfer was almost entirely laminar.

The variation in predicted blade surface heat transfer between the two flow codes for a given grid is somewhat larger than the variation due to different grids for either of the two flow analyses. Part of the differences can be attributed to differences in modeling the turbulent eddy viscosity. In the leading edge region, and prior to transition, flow code FC used the model of Forrest(1977), to augment the laminar viscosity for the effects of freestream turbulence. This model was applied to both the inner and outer regions, since this assumption would magnify any differences due to different grids on the heat transfer. Flow code FA does not increase the viscosity to account for the effect of freestream turbulence prior to transition. Both flow analyses overpredict the suction surface heat transfer when the flow is fully turbulent.

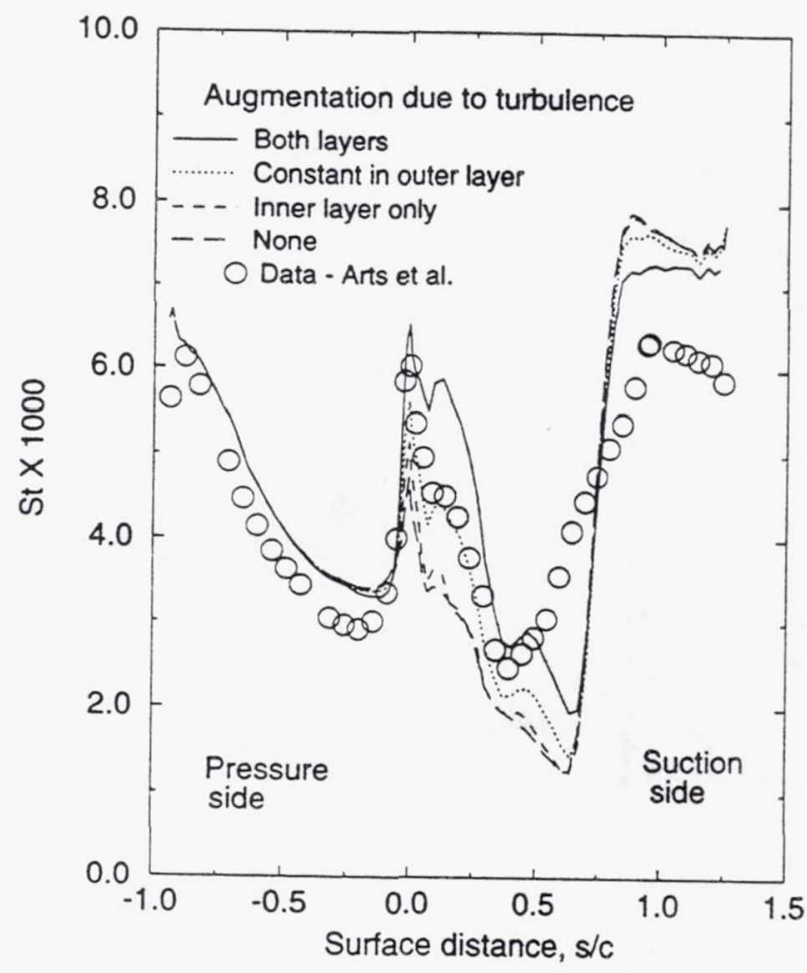

Fig. 5 Effect of model assumptions for freestream turbulence on predicted heat transfer, $R e_{2}=2.1 \times$ $10^{6}, T u=6 \%, M_{2}=0.92$, Flow code FC, grid C. 


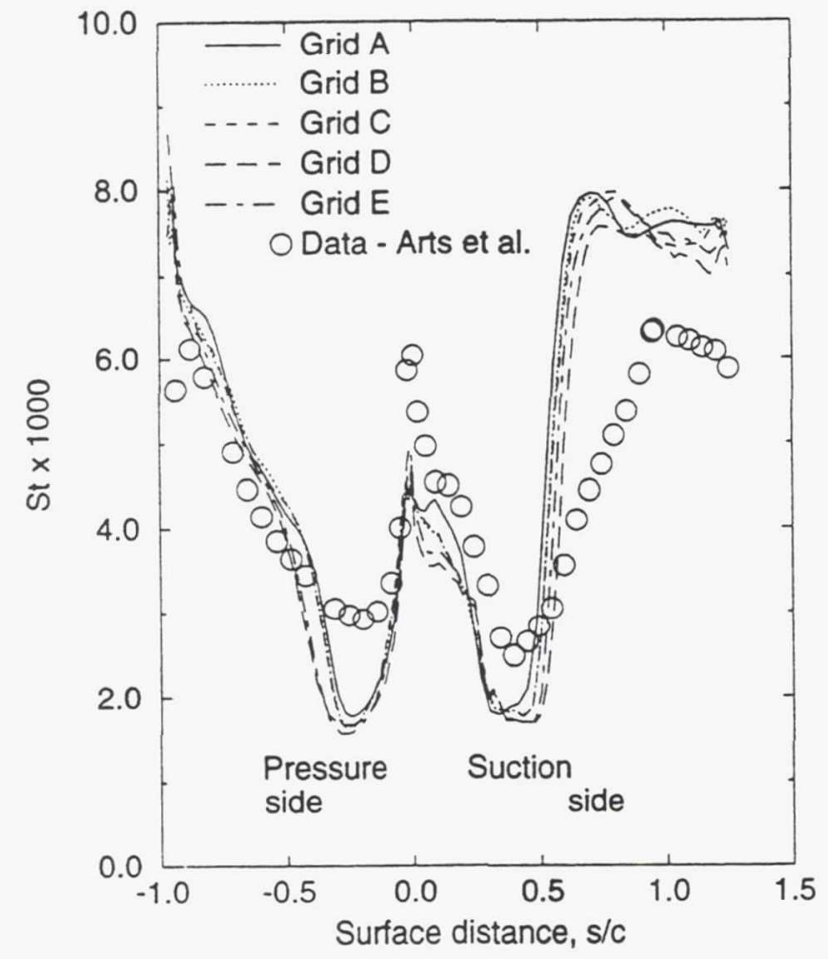

Fig. 6 Stanton number comparisons for $R e_{2}=2.1 \times$ $10^{6}, T u=6 \%, M_{2}=0.92$, Flow code FA.

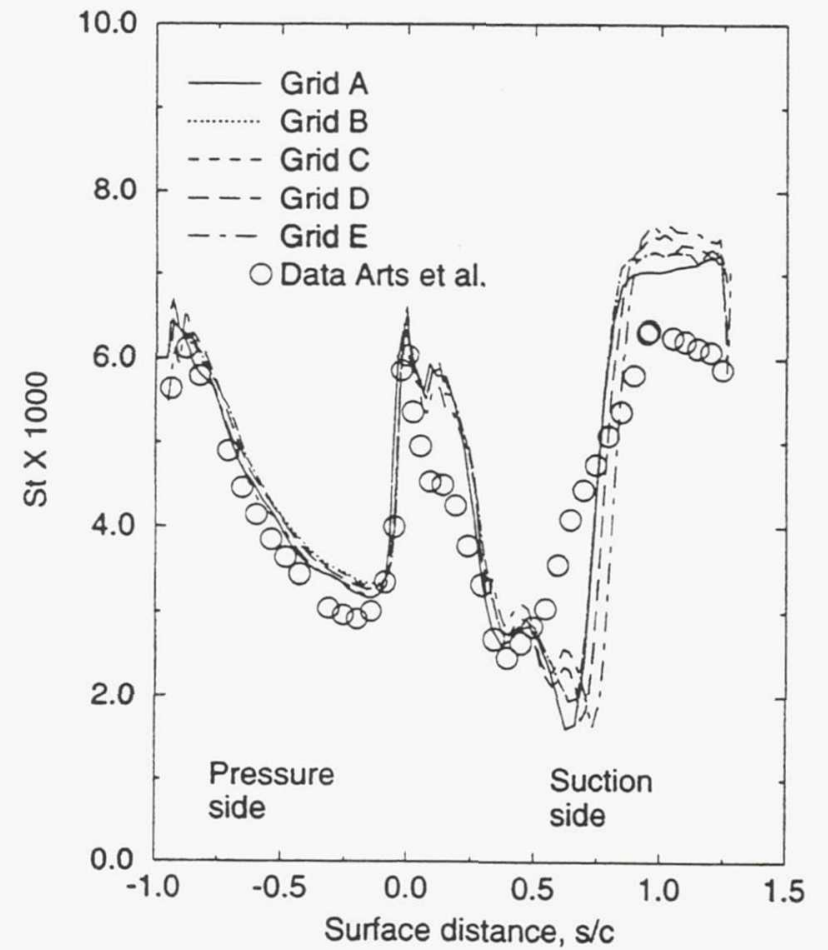

Fig. $\tau$ Stanton number comparisons for $R e_{2}=2.1 \times$ $10^{6}, T u=6 \%, M_{2}=0.92$, Flow code FC.
The results shown in figures 2 and 3 are for $R e_{2}=$ $1.16 \times 10^{6}$, while those in figures 6 and 7 are for a Reynolds number nearly twice as large. Since the same grids were used, the value of $y_{1}^{+}$for the results in figures 6 and 7 is greater. The maximum value of $y_{1}^{+}$for the high Reynolds number case was 3.8. The use of the largest value of $y_{1}^{+}$which gives accurate results minimizes the amount of near-wall grid stretching, and also allows for the smallest size grid in the blade-to-blade direction. The effect of reducing the near wall spacing is shown in figure 8 for grid D, and flow code FC. There was virtually no change in the heat transfer as the near wall spacing was reduced by a factor of 4 . Consequently, the relatively large near wall spacing used for the high Reynolds number analysis is not a cause of the differences between the measured and predicted vane heat transfer.

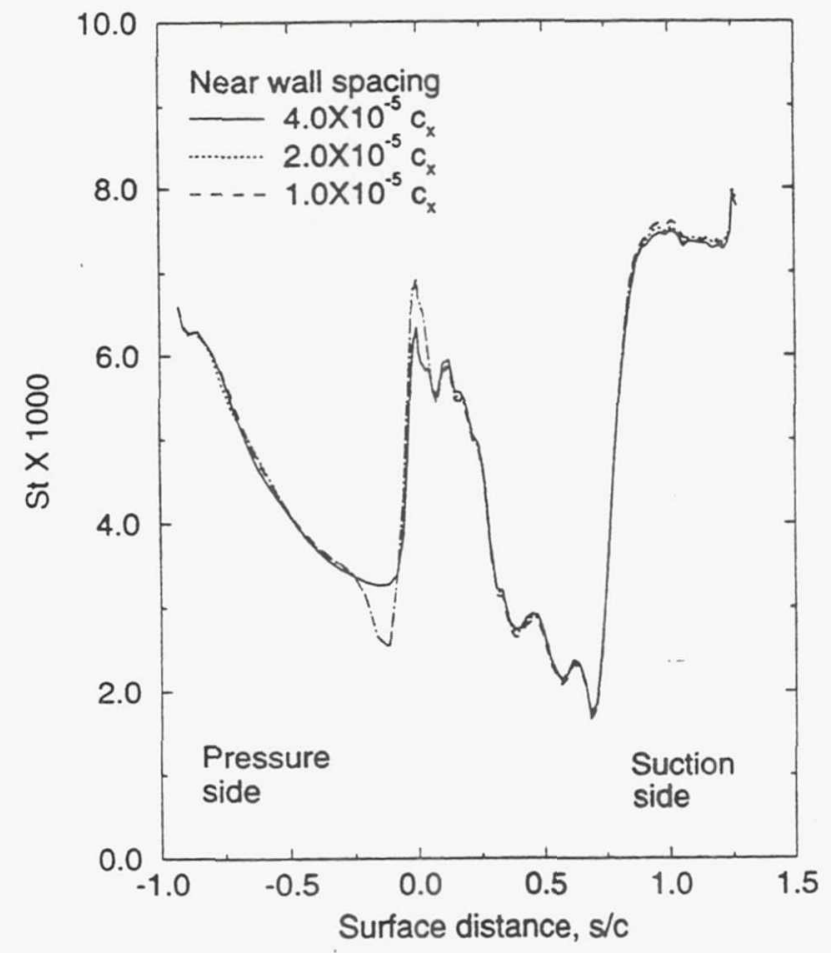

Fig. 8 Grid spacing effects on heat transfer, $R \epsilon_{2}=$ $2.1 \times 10^{6}, T u=6 \%, M_{2}=0.92$, Flow code FC, grid C.

Reducing the near wall spacing did not result in better agreement with the experimental heat transfer in the fully turbulent region. To determine if this disagreement was related to the grid properties, the effect of improving the orthogonality of the grid lines to the vane surface was examined. Figure 9 shows the angle that the grid lines make with the vane surface. If the lines were purely orthogonal, the angle would be ninety degrees. Grids B and C make identical angles with the 
blade surface, since they differ only downstream of the blade. The embedded grids, (B through E), have grid lines which maintain a constant angle for the region between the blade surface and the first circumferential inviscid grid line. For the viscous embedded grid this angle is maintained over twenty near wall spacings. Grid $\mathrm{A}$ is solved as a single grid, and the angle of the grid line with the blade surface continuously varies away from the wall. While grids B and C have the highest departure from orthogonality, it should be noted that they are both periodic in the wake. Enforcing grid matching along the cut line results in embedded grids which have a higher degree of nonorthogonality at the blade surface than either grids $\mathrm{D}$ or $\mathrm{E}$. While grids that match along the cut line can be generated using the procedure discussed by Arnone et al.(1992), they did not recommend doing so. Figure 10 shows the angle of the grid lines with the blade surface for grids D and Dn. As seen in table I, grid Dn is significantly larger in size than grid D. The use of a larger grid allows for greater orthogonality at the blade surface. However, figure 11 shows that the more orthogonal grid did not result in a significantly different heat transfer distribution.

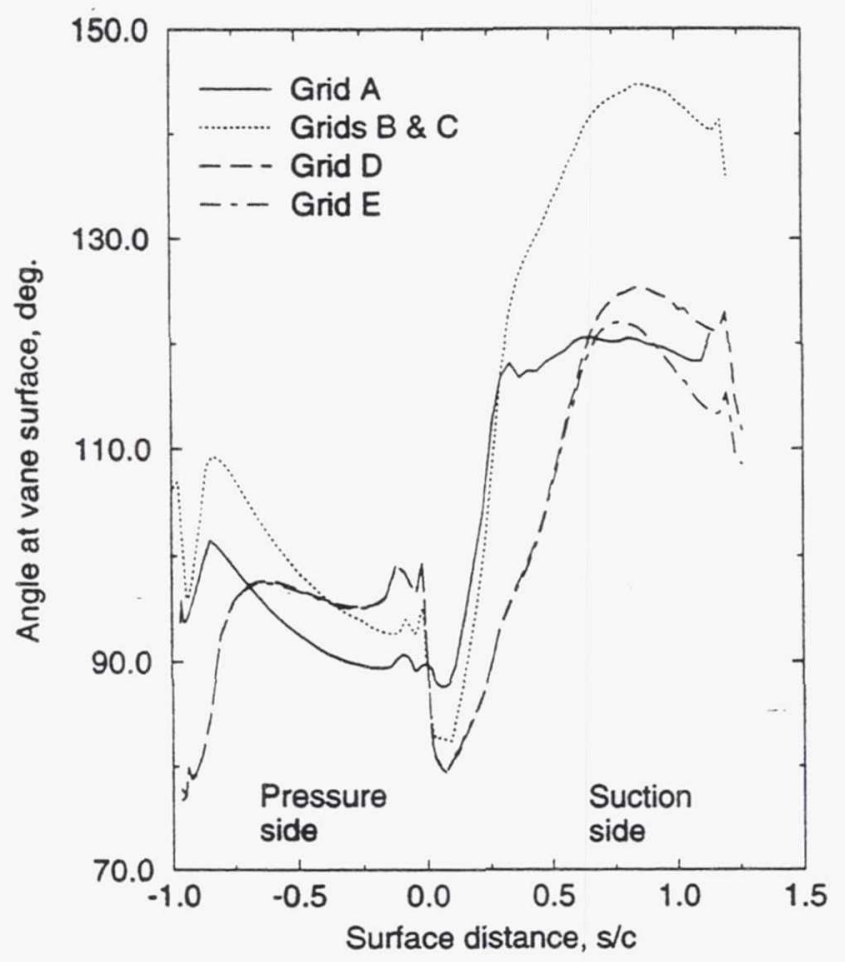

Fig. 9 Angle between grid line and vane surface.

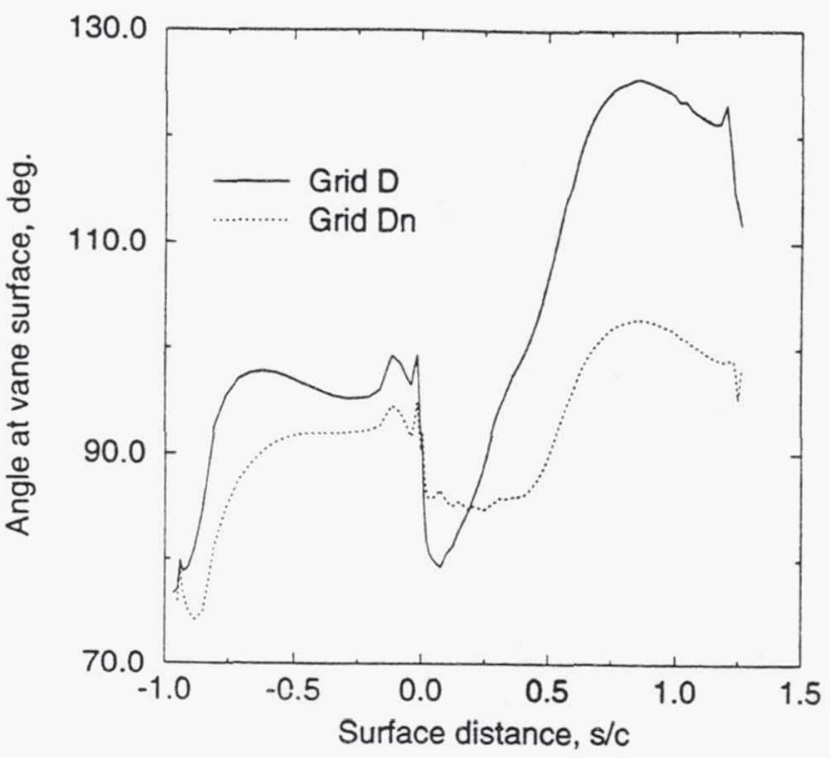

Fig. 10 Angle between grid line and blade surface for grids D and Dn.

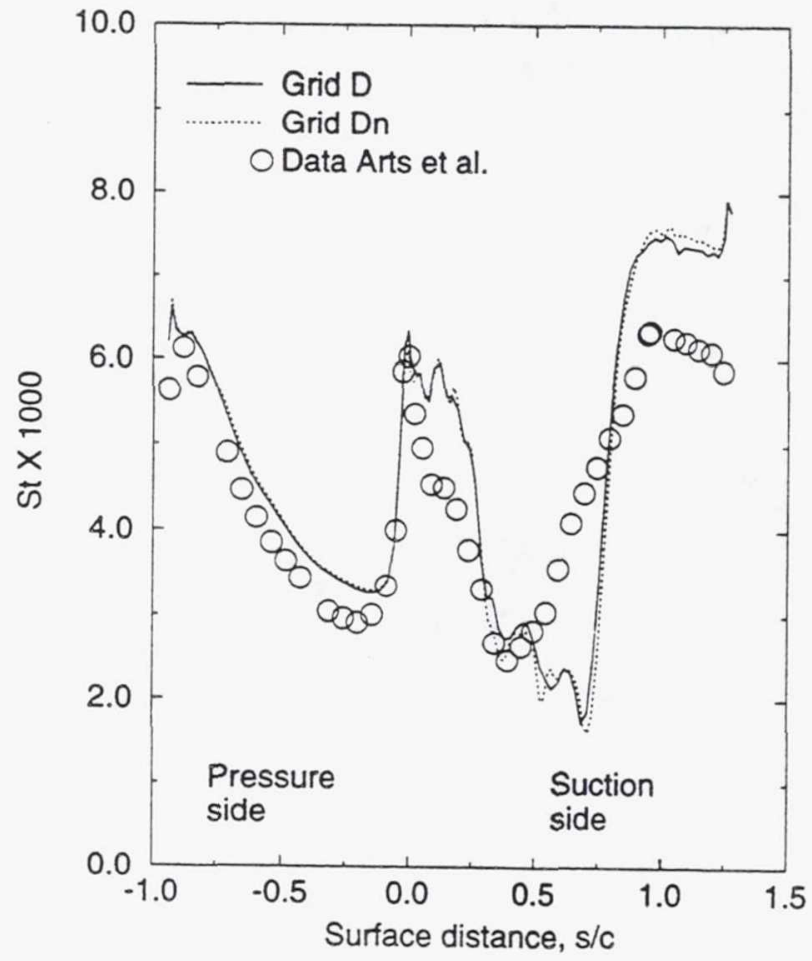

Fig. 11 Stanton number comparisons - grids D and Dn, $R \epsilon_{2}=2.1 \times 10^{6}, T u=6 \%, M_{2}=0.92$, Flow code FC. 
Table II. - Overall loss coefficient.

Total pressure distribution. Arts et al.(1990) measured the pitchwise variation in total pressure at 0.42 axial chords behind the vane. Figures 12 and 13 compare the pitchwise variation in total pressure for the five grids and the two flow solvers with the experimental data. For clarity of presentation, the minimum pressure was taken as the abscissa origin. Therefore, any variation in flow angle among the grids is not reflected in these figures. The relative grid effects are similar for both flow solvers. For grids A through D flow solver FA resulted in minimum total pressures significantly less than flow solver FC. The results obtained using grids A through $\mathrm{D}$ showed the predicted minimum total pressure lower than the experimental data. The width of the predicted wake is also smaller than the experimental wake. This indicates that the amount of diffusion of the wake predicted by the turbulence model is too small. Results obtained with flow solver FC and grid A showed a lower total pressure in the freestream region than with grids $\mathrm{B}, \mathrm{C}$, or $\mathrm{D}$. In this region the data show no loss in total pressure. Results obtained with flow solver FA and grids A through D showed no loss in total pressure in the freestream region.

Grid $\mathrm{E}$ is bent so that the grid is aligned with the axis at the downstream boundary. This bending results in a relatively coarse grid on the suction side of the cut line. The reasonably good agreement between the predicted and measured wakes for grid $\mathrm{E}$ may have been fortuitous, The numerical diffusion resulting from the coarse grid may have helped to give nearly the correct total diffusion. To verify this hypothesis, an additional bent grid, $(\mathrm{Ea})$, was generated. Table I shows that the number of points in the wake was increased considerably. Figure 14 compares the wake profiles for the two grids. The narrowing of the wake, and lowering of the minimum total pressure, in going to the finer grid is evidenced.

A comparison of the wake profile using a twoequation turbulent kinetic energy turbulence model with the wake profile using the Baldwin-Lomax turbulence model is given in figure 15. The results were obtained using grid D, and flow code FA. The twoequation model is that of Chien(1982), and details of its implementation into the flow code FA are given by Ameri and Arnone(1992). The depth of the wake using Chien's model is nearly the same as the wake depth calculated using the Baldwin-Lomax model. The width of the wake is somewhat wider using Chien's model. The wider wake region using Chien's model is due to the the model giving transition on both surfaces close to the leading edge. As shown in figure 2, the BaldwinLomax model did not result in an early transition.

\begin{tabular}{|r|r|r|r|r|r|r|r|}
\hline & \multicolumn{7}{|c|}{ Grid } \\
\hline & $\mathrm{A}$ & $\mathrm{B}$ & $\mathrm{C}$ & $\mathrm{D}$ & $\mathrm{E}$ & $\mathrm{Dn}$ & $\mathrm{Ez}$ \\
\hline Flow code & \multicolumn{6}{|c|}{$\bar{e}$} \\
\hline FA & .039 & .029 & .030 & .030 & .054 & .028 & .032 \\
FC & .035 & .026 & .023 & .029 & .024 & .027 & .024 \\
\hline \multicolumn{6}{|c|}{ Experimental - Arts et al. } & 0.029 \\
\hline
\end{tabular}

Overall loss. Table II shows the loss coefficient for the different grids obtained with the two flow solvers at an exit isentropic Mach number of 0.85. Except for the results obtained with flow code FA and grid $\mathrm{E}$, the highest calculated loss was achieved using grid A. The losses for grid $\mathrm{E}$ are different between flow codes FA and FC. But, based on the previous discussion, the results using this grid are not expected to be accurate. For both flow codes the loss levels for the other grids are reasonably close to the experimental measurements. The losses calculated using flow code FC are slightly lower than those calculated using flow code FA. Part of this difference in loss is due to the blade surface boundary layers being tripped near the trailing edge when flow code FA was used. The results for grid D are in best agreement with the experimental data.

The overall loss increased from 0.030 to 0.057 when Chien's model was used. Part of the increase was the result of the boundary layers being turbulent. A fully turbulent calculation using the Baldwin-Lomax model gave a loss coefficient of 0.041 .

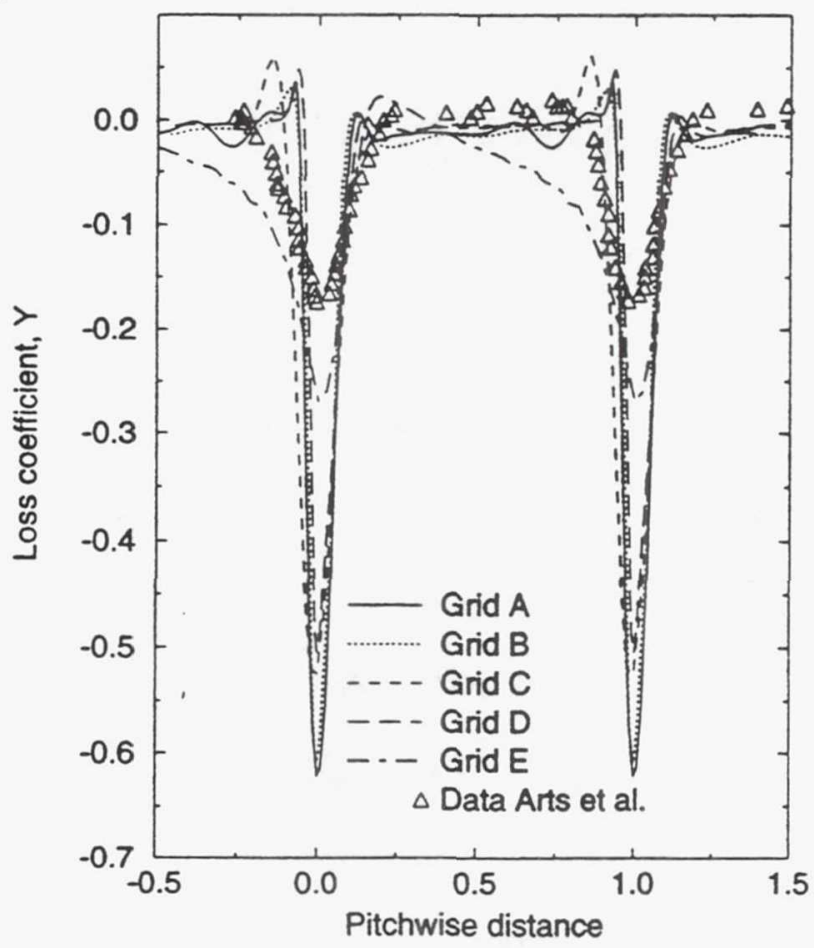

Fig. 12 Pitchwise variation in total pressure, $R e_{2}=$ 1. $\times 10^{6}, T u=1 \%, M_{2}=0.85$, Flow code FA. 


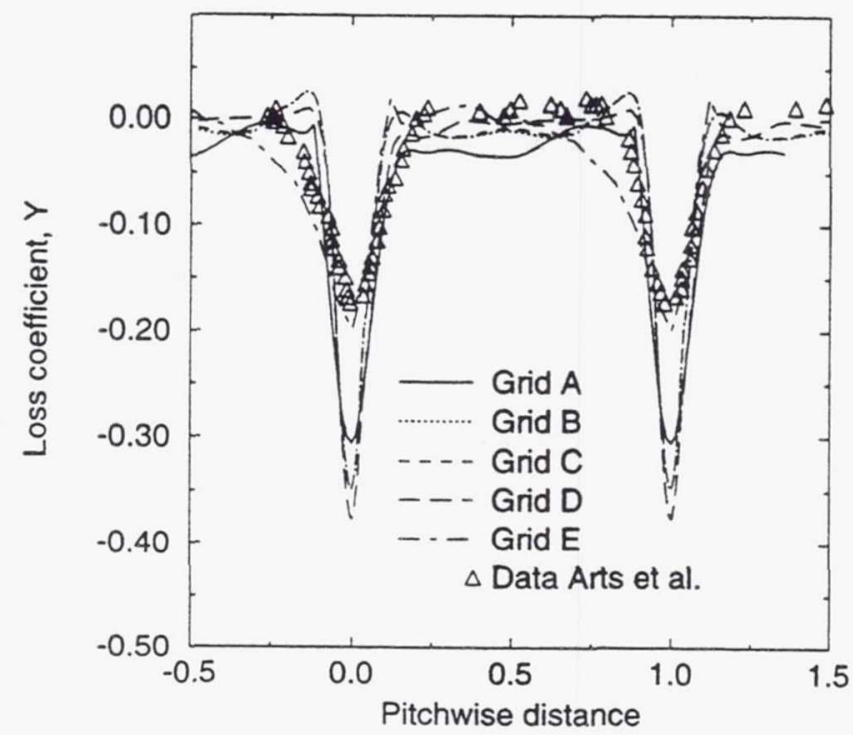

Fig. 13 Pitchwise variation in total pressure, $R e_{2}=1 . \times 10^{6}, T u=1 \%, M_{2}=0.85$, Flow code FC.

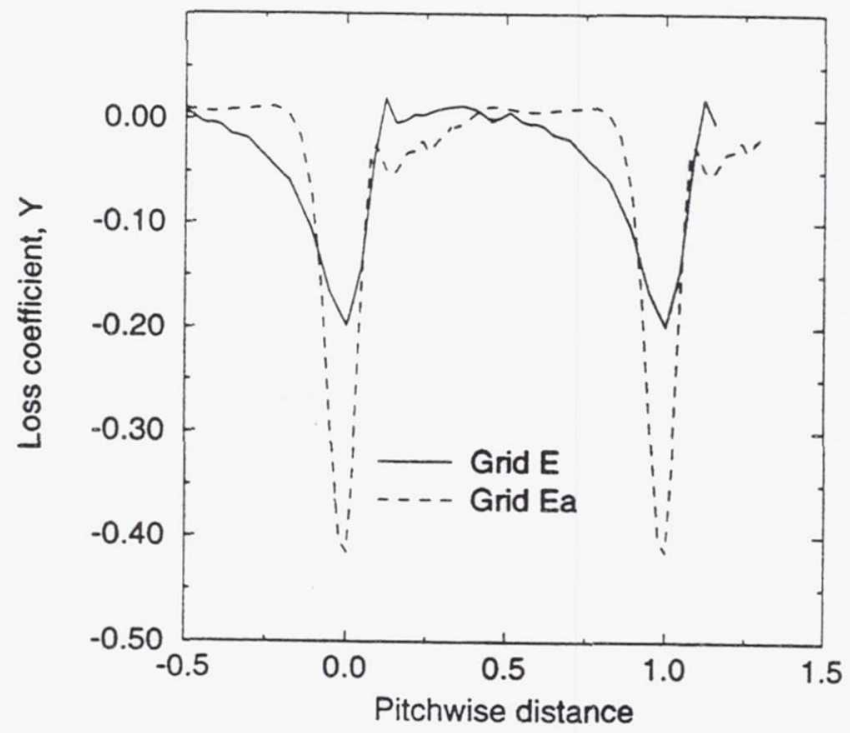

Fig. 14 Grid density effect on total pressure distribution, $R e_{2}=1 . \times 10^{6}, T u=1 \%, M_{2}=0.85$, Flow code $\mathrm{FC}$.

\section{CONCLUDING REMARKS}

The results of this investigation showed that the principle effect of different grid geometries examined was in the pressure distribution behind the vane. Four of the baseline grids resulted in an excessive decrease in total pressure at the center of the wake. The calculated

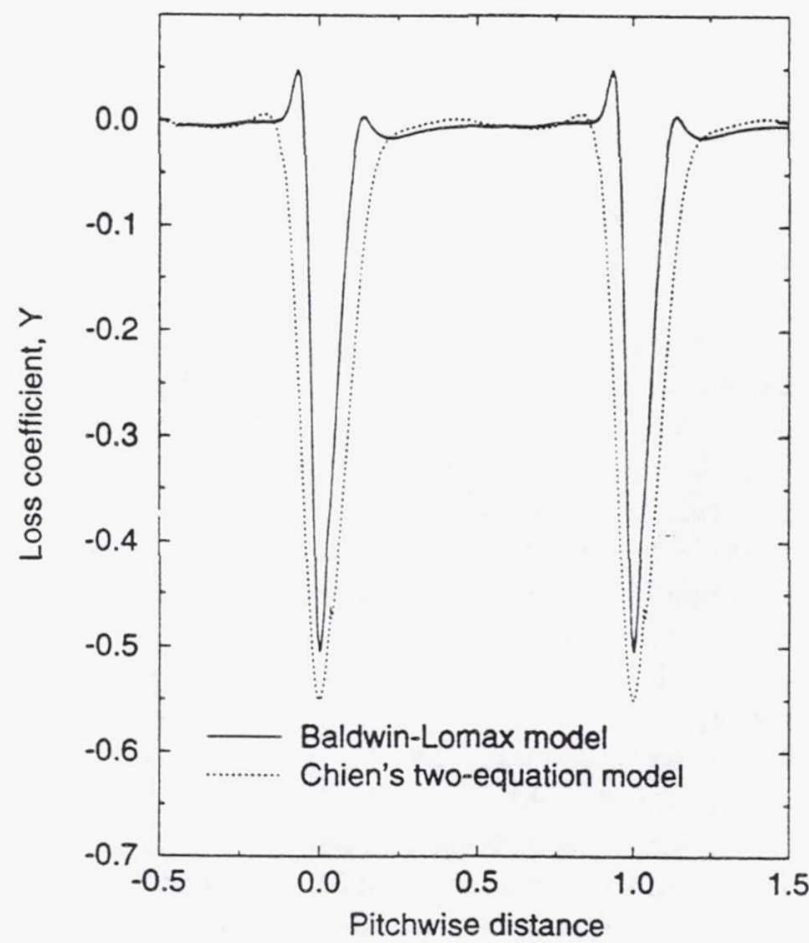

Fig. 15 Wake profiles for Baldwin-Lomax and Chien turbulence models, Grid D, Flow code FA.

wake was deeper, but more narrow than the experimental data. The implication of this is that the turbulence model used gave insufficient physical diffusion in the wake region. The fifth baseline grid, which was relatively coarse in the wake region, gave good agreement with the experimental data for the minimum pitchwise total pressure. The numerical diffusion caused by the coarse grid resulted in a more nearly correct wake profile for this grid. A similar, but denser grid(Ea), which resulted in less numerical diffusion, gave wake profiles similar to the other four baseline grids. The relative effect of different grids was the same for either of the two flow codes used.

The effect of different grid geometries on the vane surface heat transfer was small. For the low turbulence intensity case the agreement with the experimental data was good. For the high turbulence-high Reynolds number case the agreement was influenced by the choice of model to determine transition length and intermittency. The start of transition was better predicted by Mayle's transition model when the local turbulence intensity was taken as a function of the blade pressure distribution. Simon's transition length mode resulted in good agreement with the data. The choice of model to account for freestream turbulence significantly affected the predicted heat transfer. Forrest's model gave rea- 
sonably good agreement with the data when the augmented eddy viscosity was limited in the outer region of the two-layer Baldwin-Lomax turbulence model.

The overall loss distribution was not strongly affected by the choice of grid geometries. Using either flow analysis the overall loss was reasonably well predicted.

In terms of the overall results grid $\mathrm{D}$ appears to be the best choice. This grid has a non-matching condition along the cut line, and the cut line is extended in a straight line. If it is desired to maintain a matching condition along the cut line either grids $\mathrm{B}$ or $\mathrm{C}$ appear acceptable. Results obtained using either of these grids were nearly identical. From the standpoint of speed of convergence, there was no reason to prefer one grid over another. The number of time steps to obtain a converged solution was about the same for all of the grids. Surface pressure distributions were also similar for each of the baseline grids.

\section{REFERENCES}

Ameri, A.A. and Arnone, A., 1992, "Navier-Stokes Heat Transfer Predictions Using Two-Equation Turbulent Closures," AIAA Paper AIAA-92-3067.

Arnone, A, Liou, M.-S, Povinelli, L. A., 1992, "Navier- Stokes Solution of Transonic Cascade Flows Using Non-Periodic C-Type Grids," AIAA Journal of Propulsion and Power, Vol. 8, No.2, pp 410-417.

Arts, T., Lambert de Rouvroit, M., and Rutherford, A. W., 1990, "Aero-Thermal Investigation of a Highly Loaded Transonic Linear Turbine Guide Vane Cascade," von Karman Institute for Fluid Dynamics, Technical Note 174 .

Baldwin, B.S. and Lomax, H., 1978, "Thin- Layer Approximation and Algebraic Model for Separated Turbulent Flows," AIAA Paper AIAA-78-2.57.

Boyle, R.J., Giel, P.W., 1992, "Three-Dimensional Navier-Stokes Heat Transfer Predictions for Turbine Blade Rows," AIAA paper AIAA-92-3068.

Chien, K.Y., 1982, "Predictions of Channel and Boundary-Layer Flows with a Low-Reynolds-Number Turbulence Model," AIAA Journal, Vol. 20, No.1, pp 33-38.

Chima, R.V., 1987, "Explicit Multigrid Algorithm for Quasi-Three-Dimensional Flows in Turbomachinery," AIAA Journal of Propulsion and Power. Vol. 3, No.5, pp 397-405

Davis, R.L., Hobbs D.E., and Weingold, H.D., 1988, "Prediction of Compressor Cascade Performance
Using a Navier-Stokes Technique," ASME Journal of Turbomachinery, Vol. 110, No. 4, pp 520-531.

Forrest, A.E., 1977, "Engineering Predictions of Transitional Boundary layers," AGARD-CP-224.

Luo, J., and Lakshminarayana, B., 1993, "NavierStokes Analysis of Turbine Flowfield and External Heat Transfer," Presented at the Eleventh ISABE - International Symposium on Air Breathing Engines. Tokyo, Japan, Vol. 2 pp 766-780.

Harasagama, S.P., Tarada, F.H., Baumann, R., Crawford, M.E., and Neelakantan, S., 1993, "Calculation of Heat Transfer to Turbine Blading Using Two Dimensional Boundary Layer Methods," ASME paper 93-GT-79.

Mayle, R.E., 1991, "The role of Laminar-Turbulent Transition in Gas Turbine Engines," ASME Journal of Turbomachinery, Vol. 113, pp 509-537.

Micklow, G.J. Shivaraman, K., and Li, H., 1993, “A Nonperiodic Approach for Computation of Compressible Viscous Flows in Advanced Turbine Cascades," AIAA paper AIAA-93-1799.

Simon, F.F., 1994, "The Use of Transition Region Characteristics to Improve the Numerical Simulation of Heat Transfer in Bypass Transitional Flows," Presented at the Fifth International Symposium on Transport Phenomena and Dynamics of Rotating Machinery. Kaanapali, Maui, Hawaii, May 8-11, 1994 (Also NASA TM 106445).

Simon, F.F., and Stephens, C.A., 1991, "Modeling of the Heat transfer in Bypass Transitional BoundaryLayer Flows," NASA TP 3170.

Sorenson, R.L., 1980, "A Computer Program to Generate Two-Dimensional Grids About Airfoils and Other Shapes by the Use of Poisson's Equation,", NASA TM 81198.

Turner, M.G., Liang. T., Beauchamp, P., and Jennions, I.K., 1993, "The Use of Orthogonal Grids in Turbine CFD Computations," AS.ME paper 93-GT-38.

Yeuan, J.J., Hamed, A., Tabakoff, W., 1993, "Navier-Stokes Computations for Turbulent Flow Predictions in Transonic Turbine Cascade Using a Zonal Approach," ASME paper 93-GT-240. 


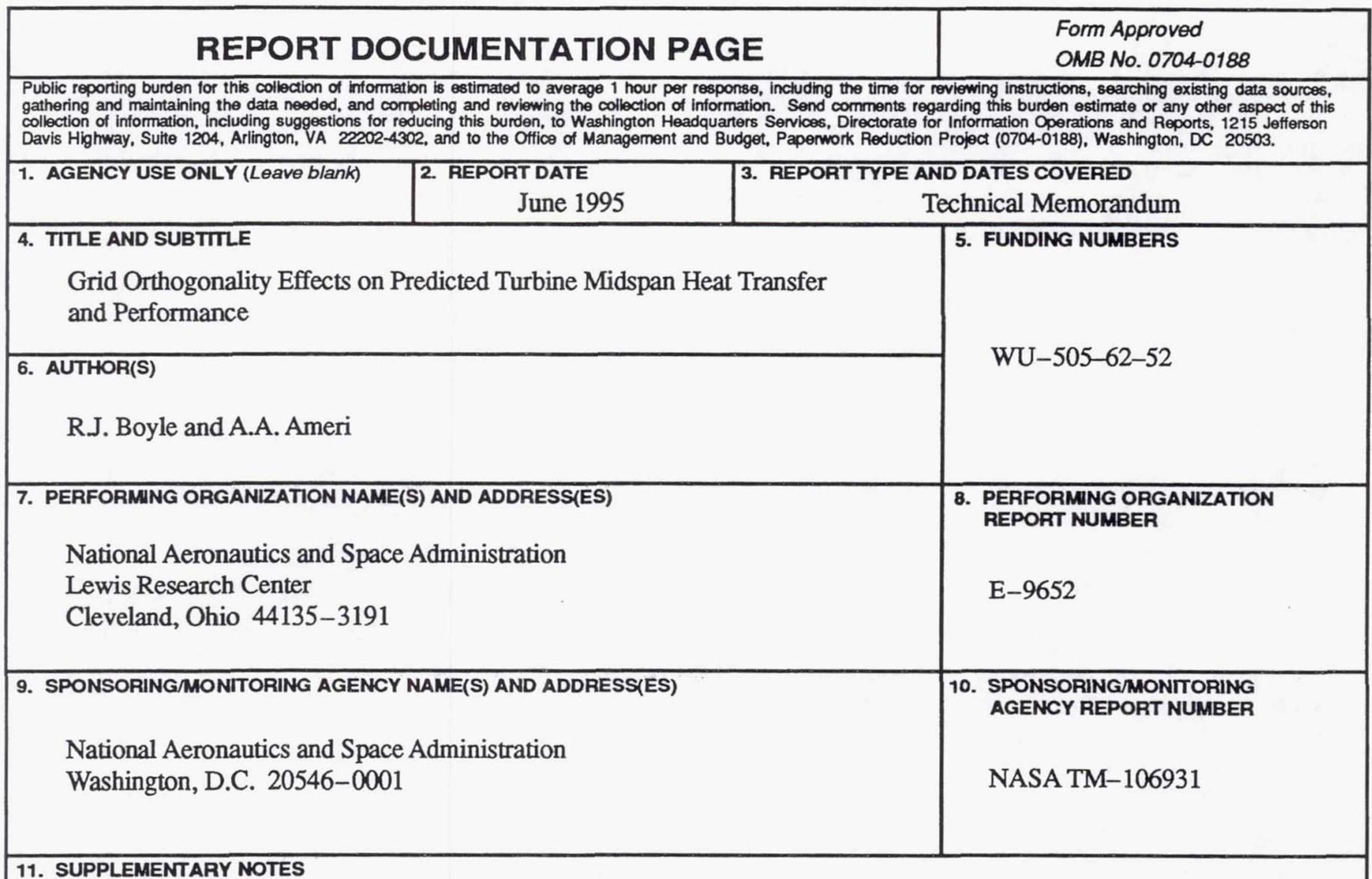

Prepared for the 39th International Gas Turbine and Aeroengine Congress and Exposition sponsored by the American Society of Mechanical Engineers, The Hague, Netherlands, June 13-16, 1994. R.J. Boyle, NASA Lewis Research Center, and A.A. Ameri, University of Kansas, Center for Research, Inc., Lawrence, Kansas 66045. Responsible person, R.J. Boyle, organization code 2640, (216) 433-5889.

\begin{tabular}{|l|l|l|l|}
\hline 12a. DISTRIBUTIONAVAILABILTY STATEMENT & 12b. DISTRIBUTION CODE
\end{tabular}

Unclassified - Unlimited

Subject Category 34

This publication is available from the NASA Center for Aerospace Information, (301) 621-0390.

13. ABSTRACT (Maximum 200 words)

The effect of five different $\mathrm{C}$ type grid geometries on the predicted heat transfer and aerodynamic performance of a turbine stator is examined. Predictions were obtained using two flow analysis codes. One was a finite difference analysis, and the other was a finite volume analysis. Differences among the grids in terms of heat transfer and overall performance were small. The most significant difference among the five grids occurred in the prediction of pitchwise variation in total pressure. There was consistency between results obtained with each of the flow analysis codes when the same grid was used. A grid generating procedure in which the viscous grid is embedded within an inviscid type grid resulted in the best overall performance.

14. SUBJECT TERMS

Grid generation; Turbine; Heat transfer

\begin{tabular}{|c|c|}
\hline 17. SECURTY CLASSIFICATION & 18. SECURTY CLASSIFICATION \\
OF REPORT & $\begin{array}{c}\text { OF THIS PAGE } \\
\text { Unclassified }\end{array}$ \\
Unclassified
\end{tabular}

NSN 7540-01-280-5500
19. SECURITY CLASSIFICATION OF ABSTRACT Unclassified 13

15. NUMBER OF PAGES

16. PRICE CODE

$$
\mathrm{A} 03
$$

\section{LIMITATION OF ABSTRACT}

